\title{
PENGEMBANGAN BUDIDAYA IKAN LELE DI KAWASAN MINAPOLITAN KABUPATEN BOGOR, JAWA BARAT: ASPEK KESESUAIAN LAHAN, IMPLEMENTASI PRODUKSI, DAN STRATEGI PENGEMBANGAN
}

\author{
I Nyoman Radiarta*), Jojo Subagja**), Adang Saputra**), dan Erlania ${ }^{* * *}$ \\ *) Pusat Penelitian dan Pengembangan Perikanan Budidaya \\ Jl. Ragunan 20, Pasar Minggu, Jakarta Selatan \\ E-mail: radiarta@yahoo.com \\ *) Balai Penelitian dan Pengembangan Budidaya Air Tawar \\ Jl. Sempur No. 1, Bogor 16154
}

(Naskah diterima: 16 Februari 2012; Disetujui publikasi: 8 Mei 2012)

\begin{abstract}
ABSTRAK
Pengembangan kawasan minapolitan harus didukung dengan ketersediaan data dan informasi di antaranya potensi lahan serta dukungan strategi pengembangannya. Kabupaten Bogor telah ditetapkan sebagai satu wilayah pengembangan minapolitan ikan lele. Tujuan dari penelitian ini adalah untuk menganalisis pengembangan budidaya ikan lele di kawasan minapolitan Kabupaten Bogor dengan melihat aspek kesesuaian lahan, implementasi produksi, dan strategi pengembangannya. Survai lapangan telah dilakukan pada bulan Juni 2011. Kesesuaian lahan dianalisis secara spasial dengan mengadopsi 1-3 sistem skor, 1 adalah kurang sesuai, dan 3 adalah sangat sesuai. Dari total potensial lokasi pengembangan sebesar 28.519 ha menunjukkan kategori sangat sesuai dan sesuai ditemukan sebesar 20.854 ha. Lokasi ini tersebar merata di empat kecamatan minapolitan. Dengan memanfaatkan sekitar $20 \%$ dari luasan yang ada, produksi ikan lele (pembesaran) per siklusnya sekitar 625.620 ton dengan semi-intensif atau 93.317 ton dengan tradisional. Beberapa strategi pengembangan budidaya ikan lele yang terbagi menjadi tiga segmen perlu diperhatikan guna mendukung kesuksesan program minapolitan ini.
\end{abstract}

KATA KUNCI: minapolitan, ikan lele, kesesuaian lahan, strategi pengembangan, Bogor

ABSTRACT: Catfish aquaculture development in the minapolitan area of Bogor District, West Java: site selection, production implementation, and development strategies. By: I Nyoman Radiarta, Jojo Subagja, Adang Saputra, and Erlania

Development of minapolitan area must be support by good data and information such as suitability potential site and development strategies. Bogor District has been selected as one of minapolitan area for catfish aquaculture development. The aim of present study is to analyze catfish aquaculture development in the minapolitan area of Bogor District with emphasize on site selection analysis, implementation production, and development strategies. Field sampling was conducted in June 2011. Several environmental and infrastructure data were analyzed using spatial models, and these data were categorized into 1-3 scoring system, 1 is least suitable and 3 is most suitable. The results show that from the total potential area of 28,519 ha; about 20,854 ha was classified as most suitable and suitable. These areas were distributed 
eventually in four sub-district minapolitan area. From the total suitable areas, if only $20 \%$ areas were utilized, production estimation for one cycle could be accounted for 625,620 ton using semi-intensive or 93,317 ton using traditional. Furthermore, development strategies for catfish aquaculture need to be carried out in order to support succesfulness of minapolitan program.

\section{KEYWORDS: minapolitan, catfish, site selection, development strategies, Bogor}

\section{PENDAHULUAN}

Kabupaten Bogor dikenal sebagai sentra produksi perikanan budidaya, khususnya sebagai produsen benih ikan air tawar di antaranya benih ikan patin, ikan bawal, ikan gurame, dan produsen ikan lele ukuran konsumsi. Luas total areal kolam air tenang yang terdapat di Kabupaten Bogor adalah $1.075,94$ ha dengan total produksi di tahun 2009 mencapai 24.072,98 ton. Produksi terbesar dihasilkan dari Kecamatan Parung dan Gunung Sindur, masing-masing sebesar 7.650,80 ton dan 6.071,64 ton (Anonimo, 2010). Salah satu upaya untuk meningkatkan produksi budidaya ikan air tawar, Kabupaten Bogor mengembangkan satu model pengembangan dengan sistem kluster yang dikenal dengan nama minapolitan. Kawasan minapolitan merupakan kawasan yang dikembangkan melalui pembentukan titik tumbuh suatu kluster kegiatan perikanan dengan sistem agribisnis berkelanjutan yang meliputi produksi, pengolahan dan pemasaran, sampai jasa lingkungan sebagai sistem kemitraan di dalam satu wilayah.

Penetapan Kabupaten Bogor sebagai lokasi pengembangan minapolitan telah dituangkan dalam surat keputusan Menteri Kelautan dan Perikanan Republik Indonesia No. KEP.32/MEN/2010. Penetapan kawasan minapolitan selaras dengan kebijakan Revitalisasi Pertanian dan Pembangunan Pedesaan (RP3) Kabupaten Bogor yang menerapkan pendekatan pengembangan pertanian berdasarkan zonasi (Anonim, 2010). Secara konstitusional, peraturan daerah yang mendukung pelaksanaan minapolitan di Kabupaten Bogor meliputi: (1) Peraturan Daerah Kabupaten Bogor No. 19/2008 tentang Rencana Tata Ruang Wilayah (RTRW) Kabupaten Bogor 2005-2025, (2) Peraturan Bupati Nomor 84/2009 tentang RP3 yang meliputi komoditas tanaman pangan, hortikultura, perkebunan, peternakan, kehutanan, dan perikanan, dan (3) Keputusan Bupati Bogor nomor 523.31/227/Kpts/Huk/2010 tentang penetapan lokasi pengembangan kawasan minapolitan di Kabupaten Bogor. Berdasarkan surat Keputusan Bupati Bogor, telah ditetapkan lokasi minapolitan di empat kecamatan yaitu Kecamatan Ciseeng, Kecamatan Parung, Kecamatan Gunung Sindur, dan Kecamatan Kemang yang mencakup 28 desa. Keempat lokasi tersebut merupakan bagian dari wilayah kecamatan di Zona IV RP3 (Anonim, 2010). Dari seluruh komoditas ikan air tawar yang telah berkembang di Kabupaten Bogor, ikan lele merupakan komoditas unggulan yang terpilih untuk dikembangkan di kawasan minapolitan ini.

Keberlanjutan kegiatan perikanan budidaya harus didukung oleh ketersediaan data dan informasi yang akurat dan terpercaya, di antaranya data potensi kawasan budidaya. Kajian potensi kawasan budidaya ikan harus mempertimbangkan berbagai aspek, meliputi lingkungan perairan (parameter fisika, biologi, dan ekologi), sosial-ekonomi dan infrastruktur (Treece, 2000). Lokasi yang sesuai untuk pengembangan perikanan budidaya akan menjamin keberlanjutan usaha budidaya, meminimalkan dampak terhadap lingkungan sekitar, dan tentunya akan meningkatkan roda perekonomian masyarakat. Analisis kesesuaian lahan untuk pengembangan ikan air tawar telah dipublikasikan untuk beberapa jenis komoditas di antaranya ikan nila (Hossain et al., 2007; Radiarta et al., 2009) dan ikan mas (Salam et al., 2005; Hossain et al., 2009). Analisis kesesuaian Iahan ini umumnya dilakukan secara spasial dengan menggunakan sistem informasi geografis (SIG; Burrough \& McDonnell, 1998). Dari hasil analisis kesesuaian lahan ini tentunya dapat digunakan sebagai dasar untuk menghitung prakiraan produksi yang dapat dihasilkan dari suatu kawasan. Sehingga proyeksi pengembangan ke depan dapat dilaksanakan dengan maksimal, yang tentunya didukung oleh adanya strategi pengembangan yang selaras. 
Tujuan dari penelitian ini adalah untuk menganalisis pengembangan budidaya ikan lele di kawasan minapolitan Kabupaten Bogor Provinsi Jawa Barat yang difokuskan pada aspek kesesuaian lahan, implementasi produksi, dan strategi pengembangannya. Analisis kesesuaian lahan dilakukan secara spasial dengan menggunakan SIG. Hasil analisis kesesuaian lahan tersebut kemudian digunakan untuk mengestimasi kemungkinan produksi yang dihasilkan dan strategi pengembangan di kawasan minapolitan Kabupaten Bogor. Hasil dari penelitian ini diharapkan dapat memberikan gambaran umum tentang pengembangan budidaya ikan lele di kawasan minapolitan Kabupaten Bogor.

\section{BAHAN DAN METODE}

Penelitian ini telah dilakukan di kawasan minapolitan Kabupaten Bogor Provinsi Jawa Barat (Gambar 1). Lokasi penelitian terdiri atas empat kecamatan meliputi Kecamatan Ciseeng, Kecamatan Gunung Sindur, Kecamatan Parung, dan Kecamatan Kemang. Dukungan sumberdaya alam dan manusia berupa kondisi iklim, lahan dan air, serta kemampuan teknis pembudidaya menjadikan Kabupaten Bogor sebagai satu sentra produksi pembenihan beberapa komoditas penting ikan air tawar. Hasil produksi benih dari kabupaten ini telah dikirimkan ke sentra pembesaran ikan air tawar di beberapa provinsi di Indonesia, di antaranya Kalimantan dan Sumatera. Faktor lain yang mendukung berkembangnya usaha perikanan budidaya di Kabupaten Bogor yaitu lokasi yang strategis sehingga memudahkan berbagai akses yang dibutuhkan untuk pengembangan kegiatan budidaya di wilayah ini. Lokasi yang berdekatan dengan Jakarta sebagai sentra perekonomian, memberikan kemudahan dalam hal akses pasar, penyediaan sarana produksi (peralatan, pakan buatan, dan obat-obatan), serta akses sarana dan prasarana pendistribusian.

\section{Parameter Penting Budidaya Ikan Lele}

Penelitian ini dilaksanakan dengan metode survai. Survai lapangan telah dilakukan pada bulan Juni 2011 . Sebanyak 39 titik pengamatan kualitas perairan berhasil dikumpulkan yang

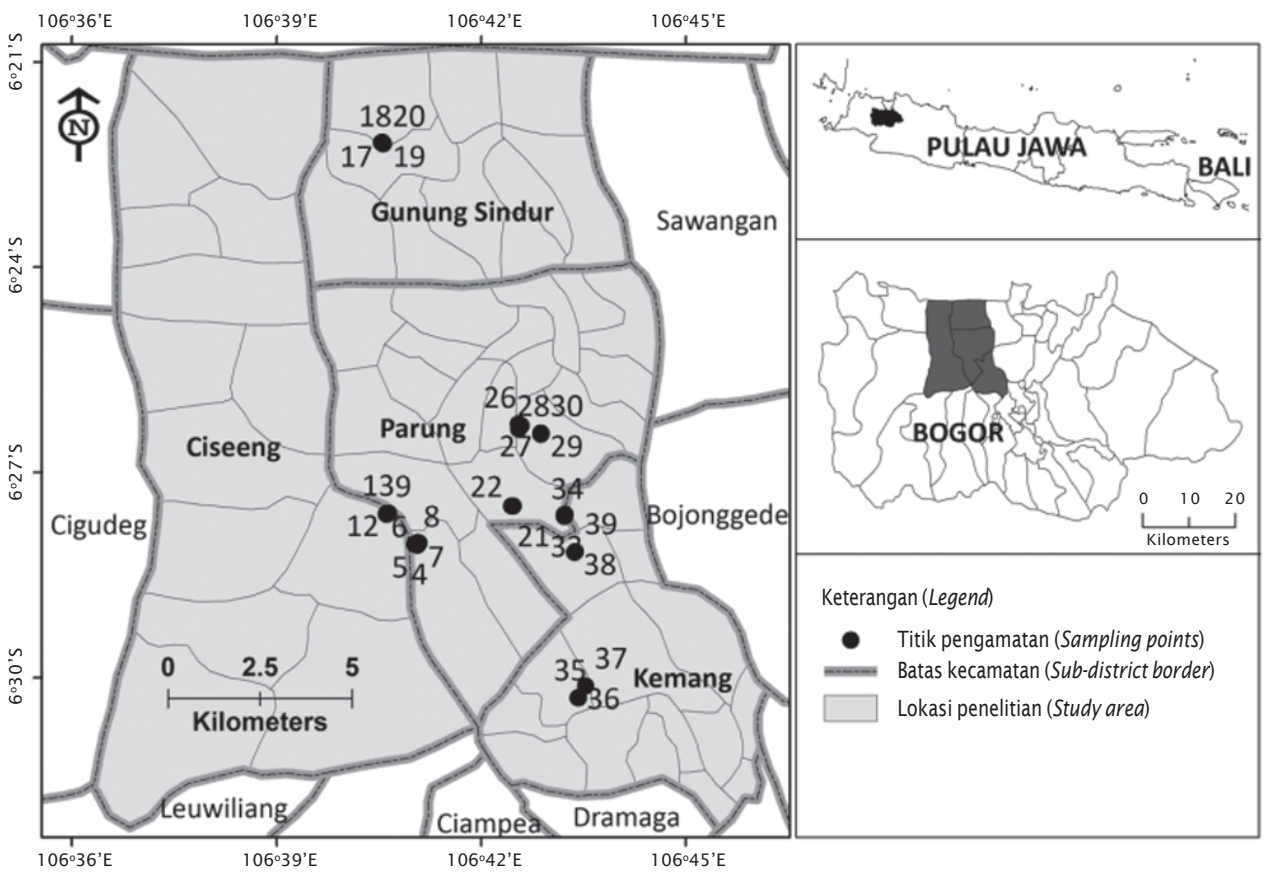

Gambar 1. Lokasi penelitian di kawasan minapolitan Kabupaten Bogor, Jawa Barat, dan distribusi titik pengamatan kualitas perairan

Figure 1. Study area in the minapolitan area of Bogor District, West Java, and distribution water quality sampling stations 
mewakili kolam pembesaran, pendederan, saluran air, dan sumber air (Gambar 1). Penentuan lokasi pengamatan disebar secara acak yang mewakili keempat kecamatan pengembangan minapolitan (Clark \& Hosking, 1986; Morain, 1999). Parameter kualitas perairan yang dikumpulkan diperoleh melalui pengukuran langsung di lapangan (suhu, pH, oksigen terlarut, TDS, dan konduktivitas) dengan menggunakan YSI 556 dan analisis laboratorium (parameter kimia dan logam berat). Posisi geografis lokasi pengamatan diperoleh dengan menggunakan global positioning system (GPS).

Data tutupan lahan dan dukungan infrastruktur diperoleh dari Peta digital Rupa Bumi Indonesia (RBI) skala 1:25.000 keluaran Badan Koordinasi Survai dan Pemetaan Nasional (Bakosurtanal). Lembar peta yang digunakan sebanyak empat lembar yaitu 1209-412 (Parung), 1209-411 (Lebak Wangi), 1209-133 (Cigedug), dan 1209-134 (Leuwiliang). Citra satelit ALOS AVNIR-2 tanggal 18 September 2009 digunakan untuk menvalidasi data peta RBI.

\section{Analisis Kesesuaian Lahan}

Kesesuaian lahan dianalisis secara spasial berdasarkan model hirarki yang diimplementasikan menggunakan perangkat lunak
ArcGIS versi 10 (Nath et al., 2000). Tujuh parameter penting yang terpilih dikelompokkan menjadi tiga sub-model (faktor) meliputi: kualitas air, pemanfaatan lahan, dan infrastruktur (Gambar 2). Untuk melakukan analisis spasial, seluruh data vector (titik, garis, dan area) yang terkumpul diinterpolasi dengan teknik inverse distance weighted (IDW) dan distance analysis Johnson \& McChow, 2001). Klasifikasi dan penentuan skor data perlu dilakukan untuk menghasilkan sistem skor yang seragam. Penelitian ini menggunakan skor 1-3 (Hossain et al., 2007; Radiarta et al., 2009) yaitu sangat sesuai $=3$, sesuai $=2$, dan kurang sesuai $=1$. Tabel 1 menyajikan tingkat kesesuaian parameter penting budidaya ikan lele. Parameter tingkat kesesuaian tersebut mengacu pada Hardjamulia et al. (1992) dan Radiarta et al. (2009). Langkah selanjutnya adalah penentuan bobot masingmasing parameter dan sub-model. Bobot ditentukan berdasarkan studi pustaka dan opini peneliti dengan menggunakan analytical hierarchy process (AHP; Saaty, 1977). Di penelitian ini, bobot masing-masing parameter dan sub-model diberikan besaran yang sama. Skor dan bobot yang telah ditetapkan akhirnya digunakan untuk menganalisis kesesuaian lahan dengan metode weighted linear combination, yang merupakan aplikasi dari multicriteria evaluation (Malczewski, 1999).

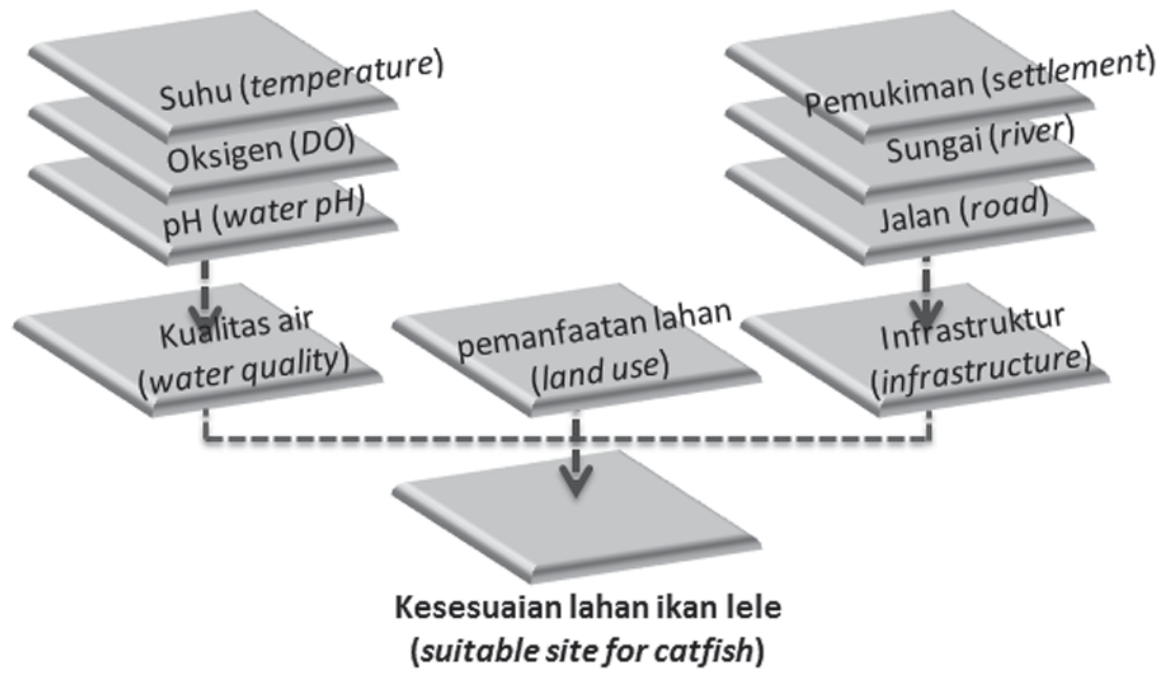

Gambar 2. Hirarki model untuk analisis kesesuaian lahan budidaya ikan lele di kawasan minapolitan Kabupaten Bogor Provinsi Jawa Barat

Figure 2. The hierarchical model to identify suitable site for catfish aquaculture in the minapolitan area of Bogor District, West Java Province 
Tabel 1. Tingkat kesesuaian parameter kualitas air dan infrastruktur untuk budidaya ikan lele di Kabupaten Bogor Provinsi Jawa Barat

Table 1. Suitability of water quality and infrastructure for catfish aquaculture in Bogor District West Java Province

\begin{tabular}{|c|c|c|c|c|}
\hline \multirow{2}{*}{$\begin{array}{c}\text { Peubah } \\
\text { Parameter }\end{array}$} & \multirow{2}{*}{$\begin{array}{l}\text { Sat uan } \\
\text { Unit }\end{array}$} & \multicolumn{3}{|c|}{$\begin{array}{l}\text { Tingkat kesesuaian } \\
\text { Suitability level }\end{array}$} \\
\hline & & $\begin{array}{l}\text { Sangat sesuai } \\
\text { Most suitable }\end{array}$ & $\begin{array}{l}\text { Sesuai } \\
\text { Suitable }\end{array}$ & $\begin{array}{l}\text { Kurang sesuai } \\
\text { Least suitable }\end{array}$ \\
\hline \multicolumn{5}{|l|}{$\begin{array}{l}\text { Kualitas perairan } \\
\text { Water quality }\end{array}$} \\
\hline $\begin{array}{l}\text { Suhu air } \\
\text { Water temperature }\end{array}$ & ${ }^{\circ} \mathrm{C}$ & $28-30$ & $20-28 ; 30-35$ & $<20 ;>35$ \\
\hline $\begin{array}{l}\mathrm{pH} \text { air } \\
\text { Water } \mathrm{pH}\end{array}$ & & $6-8$ & $4-6 ; 8-9$ & $<4 ;>9$ \\
\hline $\begin{array}{l}\text { Oksigen te rlarut } \\
\text { Dissolve oxygen }\end{array}$ & $\mathrm{mg} / \mathrm{L}$ & $>4$ & $2-4$ & $<2$ \\
\hline $\begin{array}{l}\text { Tipe/jenis pe manfaatan lahan } \\
\text { Land use types }\end{array}$ & & $\begin{array}{l}\text { Akuakultur; } \\
\text { Tegalan }\end{array}$ & Sawah & Perkebunan \\
\hline \multicolumn{5}{|l|}{$\begin{array}{l}\text { Infrast rukt ur } \\
\text { Infrast ruct ure }\end{array}$} \\
\hline $\begin{array}{l}\text { Jarak dari jalan } \\
\text { Distance to road }\end{array}$ & $\mathrm{m}$ & $50-500$ & 500-1,000 & $<50 ;>1,000$ \\
\hline $\begin{array}{l}\text { Jarak dari sungai } \\
\text { Distance to river }\end{array}$ & $\mathrm{m}$ & $<500$ & $500-1,000$ & $>1,000$ \\
\hline $\begin{array}{l}\text { Jarak dari perkampungan } \\
\text { Distance to settlement }\end{array}$ & $\mathrm{m}$ & $50-400$ & $400-800$ & $<50 ;>800$ \\
\hline
\end{tabular}

\section{Analisis Implementasi Produksi dan Strategi Pengembangan}

Selain data kualitas perairan, wawancara dengan beberapa responden (pembudidaya ikan dan pengurus kelompok pembudidaya) dilakukan guna memperoleh data dan informasi tentang kondisi budidaya ikan lele dan pelaksanaan program minapolitan di lokasi penelitian. Implementasi produksi ikan lele dihitung berdasarkan luasan tingkat kesesuaian lahan yang diperoleh dari analisis spasial. Perhitungan produksi ini disesuaikan dengan tingkat teknologi yang berkembang di lokasi penelitian yaitu semiintensif dan tradisional. Selanjutnya, strategi pengembangan budidaya ikan lele disintesis secara deskriptif berdasarkan data hasil wawancara.

\section{HASIL DAN BAHASAN}

\section{Kondisi Kualitas Perairan dan Pemanfaatan Lahan}

Kondisi sumber air adalah salah satu aspek penting yang terkait dengan biosecurity dalam Best Management Practices untuk kegiatan budidaya ikan (Hollingsworth et al., 2006). Air yang digunakan oleh masyarakat di Kabupaten Bogor untuk kegiatan budidaya ikan berasal dari berbagai sumber antara lain sungai, aliran anak sungai, dan beberapa situ yang terdapat di sekitar lokasi budidaya. Kualitas air untuk kegiatan budidaya ditentukan oleh kualitas dari sumber air yang digunakan. Air selalu menjadi faktor pembatas dalam produksi ikan skala komersial, oleh karena itu, kondisi kualitas perairan perlu diketahui secara baik guna memantau kemungkinan terjadinya 
pencemaran terhadap sumber air yang digunakan (Swann, 1996).

Hasil analisis kualitas perairan di kawasan minapolitan Kabupaten Bogor ditunjukkan pada Tabel 2. Kisaran suhu air, total dissolve solid (TDS), dan kecerahan air umumnya sesuai dengan kondisi yang dipersyaratkan untuk budidaya lele berdasarkan SNI 01-6484.32000, SNI 01-6484.4-2000, dan SNI 01-6484.52002. Nilai $\mathrm{pH}$ yang cukup rendah dengan kisaran antara 3,97-4,77 terpantau di beberapa lokasi yaitu di saluran/sumber air Desa Putat Nutug (Ciseeng), Situ Iwul (Parung), dan Situ Jampang Pulo (Kemang). Hal ini disebabkan karena pengukuran dilakukan pada waktu pagi hari di mana aktivitas fotosintesis oleh tumbuhan dan fitoplankton yang berperan dalam menurunkan $\mathrm{CO}_{2}$ di air belum berlangsung optimal, sehingga $\mathrm{pH}$ air masih rendah. Menurut Durborow (2000), nilai pH 4-11 merupakan titik asam dan basa letal untuk ikan, sedangkan $\mathrm{pH}$ optimum adalah antara 6,5-9,0.

Kandungan oksigen yang cukup rendah ditemukan di Situ Iwul (<3 mg/L) (Table 2), yang merupakan sumber air kegiatan budidaya perikanan di Kecamatan Parung. Nilai tersebut dimungkinkan karena pengukuran dilakukan pada pagi hari sehingga kadar oksigen terlarut di air masih rendah akibat proses respirasi organisme akuatik pada malam harinya, sedangkan pada pagi hari proses fotosintesis yang merupakan salah satu sumber $\mathrm{O}_{2}$ di air belum berlangsung optimal. Hasil penelitian
Purba \& Khan (2010) juga menunjukkan bahwa kandungan $\mathrm{O}_{2}$ pada pagi hari rendah sedangkan $\mathrm{CO}_{2}$ tinggi yang menyebabkan nilai $\mathrm{pH}$ air rendah. Nilai kandungan nitrit terukur $<1$ $\mathrm{mg} / \mathrm{L}(0,00-0,106 \mathrm{mg} / \mathrm{L})$, kondisi ini sesuai dengan persyaratan untuk air yang dapat digunakan dalam kegiatan budidaya ikan. Sedangkan nilai pengukuran amonia berkisar antara 0,148-0,967 mg/L di mana nilai tersebut masih dalam kisaran yang layak untuk budidaya ikan lele (Hardjamulia et al., 1992).

Selain ditinjau dari sifat fisik dan kimia air, kesesuaian suatu perairan untuk dijadikan lahan budidaya ikan lele juga dinilai dari beban pencemaran terutama yang berasal dari logam berat dan pestisida. Tingkat pencemaran logam berat (Cadmium (Cd) dan Timbal $(\mathrm{Pb})$ dari perairan kawasan minapolitan Kabupaten Bogor umumnya masih dalam kisaran kriteria kualitas air golongan C (untuk pertanian dan perikanan) sehingga keberadaannya masih dapat ditolerir oleh organisme akuatik seperti ikan (Tabel 3).

Konsentrasi logam berat Cd yang cukup tinggi (> 0,1 mg/L) ditemukan di Sungai Cibeteng, Desa Putat Nutug, Kecamatan Ciseeng yaitu sebesar 1,74 mg/L (Tabel 3). Tingginya kandungan $\mathrm{Cd}$ yang terdapat dalam air ini diduga berasal dari limbah aktivitas penduduk (domestik) dan industri yang terdapat sepanjang aliran sungai tersebut. Sedangkan konsentrasi $\mathrm{Pb}$ masih di bawah persyaratan kualitas air untuk budidaya perikanan air tawar (Anonim, 2001).

Tabel 2. Hasil pengukuran kualitas perairan di kawasan minapolitan Kabupaten Bogor Provinsi Jawa Barat

Table 2. Range of water quality measurement in the minapolitan area of Bogor District West Java Province

\begin{tabular}{lccc}
\hline \multicolumn{1}{c}{$\begin{array}{c}\text { Parameter } \\
\text { Variable }\end{array}$} & $\begin{array}{c}\text { Satuan } \\
\text { Unit }\end{array}$ & $\begin{array}{c}\text { Kisaran } \\
\text { Range }\end{array}$ & $\begin{array}{c}\text { Rataan } \\
\text { Average } \pm \text { SD }\end{array}$ \\
\hline Kecerahan (Transparency) & $\mathrm{cm}$ & $2-200$ & $17.92 \pm 37.55$ \\
Kedalaman (Waterdepth) & $\mathrm{cm}$ & $10-200$ & $53.89 \pm 39.54$ \\
Suhu air (Temperature) & ${ }^{\circ} \mathrm{C}$ & $27.76-34.2$ & $30.43 \pm 1.51$ \\
$\mathrm{pH}$ & - & $3.97-8.16$ & $6.51 \pm 1.07$ \\
Oksigen terlarut (Dissolve oxygen) & $\mathrm{mg} / \mathrm{L}$ & $0.73-9.17$ & $4.85 \pm 2.08$ \\
TDS (Total dissolve solid) & $\mathrm{mg} / \mathrm{L}$ & $0.043-0.937$ & $0.15 \pm 0.21$ \\
Konduktivitas (Conductivity) & $\mu \mathrm{mhos} / \mathrm{cm}$ & $0.071-1.567$ & $0.22 \pm 0.28$ \\
Amonia $\left(\mathrm{N}^{-\mathrm{NH}_{3}}\right)$ & $\mathrm{mg} / \mathrm{L}$ & $0.148-0.967$ & $0.54 \pm 0.31$ \\
Nitrit $\left(\mathrm{N}-\mathrm{NO}_{2}\right)$ & $\mathrm{mg} / \mathrm{L}$ & $0.000-0.106$ & $0.04 \pm 0.03$ \\
\hline
\end{tabular}


Tabel 3. Hasil pengukuran kandungan logam berat dan residu pestisida pada perairan di kawasan minapolitan Kabupaten Bogor Provinsi Jawa Barat

Table 3. Pesticide residues and heavy metal measurement in the minapolitan area of Bogor District West Java Province

\begin{tabular}{|c|c|c|c|c|c|c|}
\hline \multirow{2}{*}{$\begin{array}{l}\text { Kecamatan } \\
\text { Sub-dist rict }\end{array}$} & \multirow{2}{*}{$\begin{array}{c}\text { Desa } \\
\text { Village }\end{array}$} & \multicolumn{2}{|c|}{$\begin{array}{l}\text { Logam berat } \\
\text { Heavy metal } \\
\quad(\mathrm{mg} / \mathrm{L})\end{array}$} & \multicolumn{3}{|c|}{$\begin{array}{c}\text { Residu pestisida } \\
\text { Pest icide residue } \\
\text { (mg/L) }\end{array}$} \\
\hline & & $\underset{(\mathrm{mg} / \mathrm{L})}{\mathrm{Cd}}$ & $\begin{array}{c}\mathrm{Pb} \\
(\mathrm{mg} / \mathrm{L})\end{array}$ & Klorpirifos & Paration & Profenofos \\
\hline Ciseeng & Putat Nutug & 1.74 & $<0.01$ & $\mathrm{td}$ & $\mathrm{td}$ & $\mathrm{td}$ \\
\hline Gunung Sindur & Pabuaran & 0.07 & $<0.01$ & $\mathrm{td}$ & $\mathrm{td}$ & 0.010 \\
\hline Parung & Iwul & $<0.01$ & $<0.01$ & $\mathrm{td}$ & 0.247 & 0.505 \\
\hline Kemang & Jampang & 0.05 & $<0.01$ & 0.010 & $\mathrm{td}$ & $\mathrm{td}$ \\
\hline
\end{tabular}

$\mathrm{td}=$ tidak terdeteksi $($ not recorded)

Perairan bertindak sebagai tempat penampungan utama bagi residu pestisida yang bersifat persisten seperti golongan organofosfat. Masuknya pestisida ke dalam perairan melalui berbagai jalur, antara lain: pemakaian langsung untuk membasmi hama tanaman, buangan limbah perkotaan (domestik) dan industri, limpasan dari areal persawahan, pencucian melalui tanah, penimbunan aerosol dan partikulat, serta curah hujan. Konsentrasi pestisida golongan organofosfat dalam contoh air yang berasal dari Kecamatan Ciseeng, Gunung Sindur, dan Kemang masih di bawah batas maksimal residu. Akan tetapi kondisi berbeda ditemukan pada contoh air dari Desa Iwul, Kecamatan Parung di mana residu pestisida yang berasal dari perairan Situ Iwul sebagai sumber air untuk kolam budidaya lele konsentrasinya $>0,1 \mathrm{mg} / \mathrm{L}$ yaitu paration sebesar $0,247 \mathrm{mg} / \mathrm{L}$ dan profenofos 0,505 mg/L. Besarnya konsentrasi tersebut mengindikasikan bahwa penggunaan pestisida organofosfat di daerah ini cukup tinggi. Masalah ini perlu mendapat perhatian serius karena reridu pestisida ada yang bersifat karsinogenik yang dapat mempengaruhi kesehatan manusia.

Kondisi pemanfaatan lahan perlu diperhatikan untuk pengembangan budidaya ikan lele di kawasan minapolitan Kabupaten Bogor. Berdasarkan data peta RBI keluaran Bakosurtanal, pemanfaatan lahan pada empat kecamatan kawasan minapolitan terbagi menjadi: belukar, empang, hutan, kebun, pemukiman, tanah kosong, sawah, perairan, dan tegalan (Gambar 3; Tabel 4). Pemanfaatan lahan di kawasan ini didominasi oleh perkebunan dan sawah dengan luasan masingmasing 9.035 ha dan 6.292 ha. Berdasarkan tingkat kesesuaian lahan, kawasan hutan dan pemukiman dikategorikan sebagai pembatas (constraint) untuk lahan pengembangan budidaya ikan lele. Kedua kategori tutupan lahan ini memiliki luasan masing-masing 1.178 ha dan 6.091 ha (Tabel 4).

\section{Kesesuaian Lahan Budidaya Ikan Lele}

Hasil analisis spasial terhadap sub-model kualitas air, infrastruktur, dan pemanfaatan lahan disajikan pada Gambar 4 dan Tabel 5. Untuk sub-model kualitas air yang masuk dalam kategori sangat sesuai seluas 26.834 ha (94\%) tersebar di Kecamatan Ciseeng, Kecamatan Gunung Sindur, sebagian Kecamatan Parung dan Kecamatan Kemang (Gambar 4a). Selebihnya seluas 1.683 ha (6\%) masuk dalam kategori sesuai yang tersebar di sebagian wilayah Kecamatan Parung dan Kecamatan Kemang. Untuk percepatan pengembangan budidaya ikan lele di lokasi penelitian sangat didukung oleh kondisi pemanfaatan lahan.

Berdasarkan pemanfaatan lahan, kategori sangat sesuai memiliki luasan sekitar 5.423 ha (19\%) tersebar di Gunung Sindur, Parung, dan Kemang, kemudian kategori sesuai seluas 6.292 ha (22\%) tersebar di Parung, Kemang, dan Ciseeng (Gambar 4b). Kategori kurang sesuai seluas 9.139 ha (32\%) tersebar di Ciseeng dan Parung. Pada sub-model ini, ditemukan sekitar $27 \%$ area potensial (pe- 


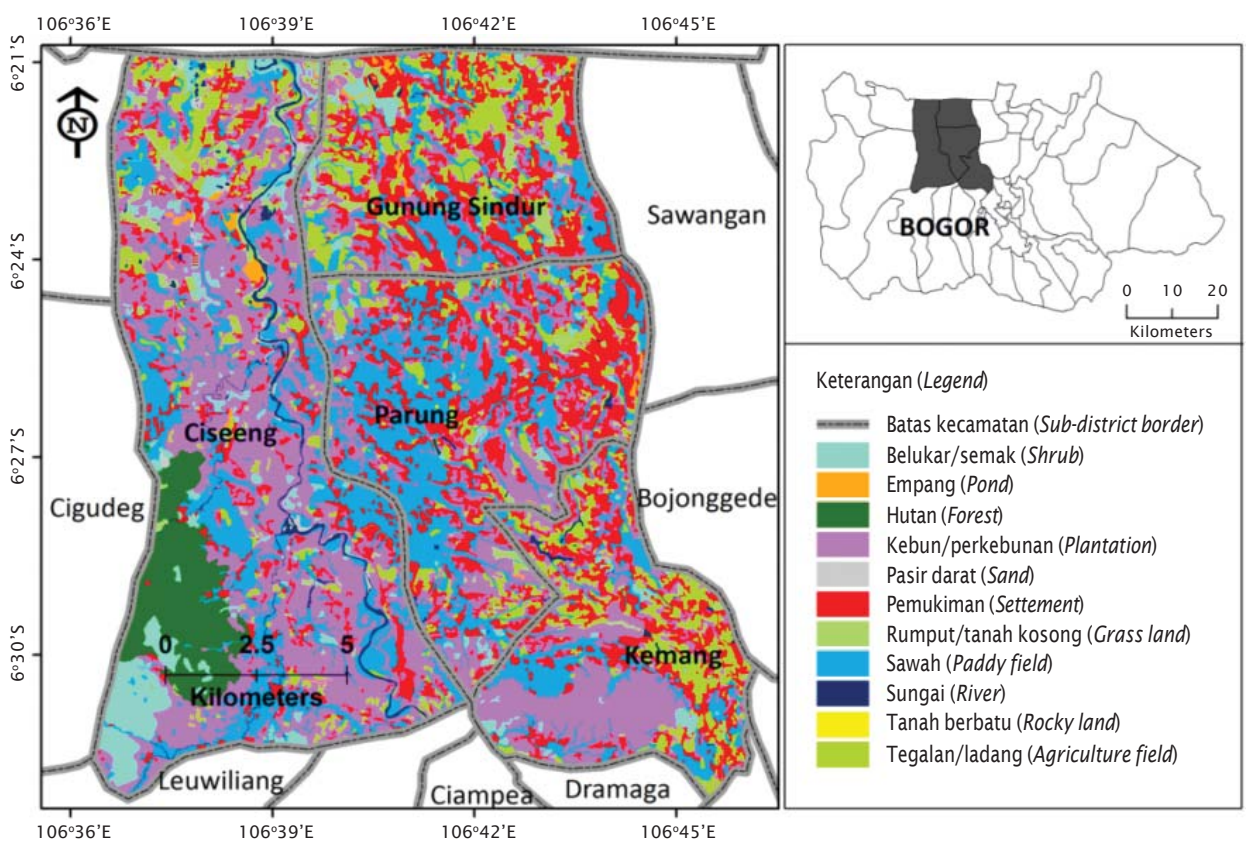

Gambar 3. Jenis pemanfaatan lahan di kawasan minapolitan Kabupaten Bogor, Jawa Barat

Figure 3. Land use types in the minapolitan area of Bogor District, West Java

Tabel 4. Pemanfaatan lahan dan tingkat kesesuaiannya untuk budidaya ikan lele

Table 4. Land use types and its suitability score for catfish aquaculture

\begin{tabular}{|c|c|c|c|}
\hline \multirow{2}{*}{$\begin{array}{l}\text { Pemanfaat an lahan } \\
\text { Land Use types }\end{array}$} & \multicolumn{2}{|c|}{ Luasan (Area) } & \multirow{2}{*}{$\begin{array}{l}\text { Tingkat kelayakan } \\
\text { Suit ability score }\end{array}$} \\
\hline & ha & $\%$ & \\
\hline Belukar/semak (Shrub) & 1.304 & 4 & Sangat sesuai (Most suitable) \\
\hline Empang (Pond) & 139 & 1 & Sangat se suai (Most suitable) \\
\hline Hutan (Forest) & 1.178 & 4 & Pembatas (Constraint) \\
\hline Kebun/perkebunan (Plantation) & 9.035 & 31 & Kurang se suai (Less suitable) \\
\hline Pasir darat (Sandy area) & 99 & 1 & Kurang sesuai (Less suitable) \\
\hline Pemukiman (Settlement) & 6.091 & 21 & Pembatas (Constraint) \\
\hline Rumput/tanah kosong (Grass land) & 830 & 3 & Sangat se suai (Most suitable) \\
\hline Sawah (Paddy field) & 6.292 & 22 & Sesuai (Suitable) \\
\hline Sungai (River) & 396 & 1 & Pembatas (Constraint) \\
\hline Tanah berbatu (Rocky land) & 5 & 1 & Kurang sesuai (Less suitable) \\
\hline Tegalan/ladang (Agriculture field) & 3.150 & 11 & Sangat se suai (Most suitable) \\
\hline Total & 28.519 & 100 & \\
\hline
\end{tabular}

mukiman dan hutan) sebagai pembatas (constraint) untuk kegiatan budidaya ikan lele. Penggunaan faktor pembatas untuk pemanfaatan lahan hutan dan perkampungan juga telah digunakan oleh Hossain et al. (2007) dan Radiarta et al. (2009) dalam kajian mereka mengenai kesesuaian lahan budidaya udang dan ikan nila. 
(a) Kualitas perairan Water quality sub-model

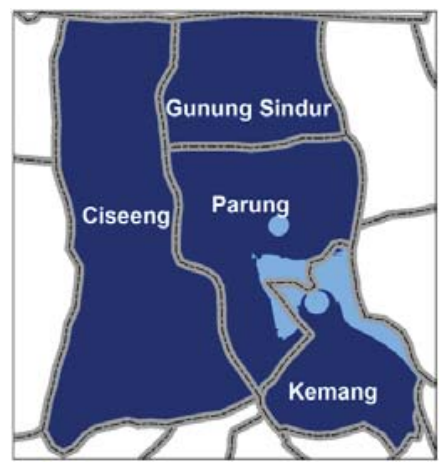

Keterangan (Legend)

Batas kecamatan (Sub-district
Sangat sesuai (Most suitable)
Sesuai (Suitable) (b) Pemanfaatan Iahan Land use sub-model

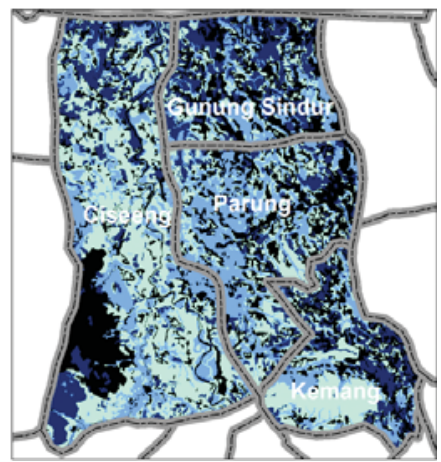

Kurang sesuai (Least suitable)

Pembatas (Constraint)

Gambar 4. Peta tingkat kesesuaian lahan parameter kualitas air (a), pemanfaatan lahan (b), dan infrastruktur (c) untuk budidaya ikan lele di kawasan minapolitan Kabupaten Bogor Provinsi Jawa Barat

Figure 4. Map of suitability sites for water quality (a), land use (b), and infrastructure (c) for catfish aquaculture in the minapolitan area of Bogor District, West Java Province

Tabel 5. Luasan (ha) dan persentase (\%) tingkat kesesuaian lahan untuk budidaya ikan lele di kawasan minapolitan Kabupaten Bogor Provinsi Jawa Barat. Luasan area potensial adalah 28.519 ha

Table 5. Areas (ha) and different suitability levels (\%) for catfish aquaculture in the minapolitan area of Bogor District West Java Province. Total potential area is 28,519 ha

\begin{tabular}{|c|c|c|c|c|c|c|c|c|}
\hline \multirow{2}{*}{$\begin{array}{l}\text { Parameter } \\
\text { Variable }\end{array}$} & \multicolumn{2}{|c|}{$\begin{array}{l}\text { Sangat sesuai } \\
\text { Most suit able }\end{array}$} & \multicolumn{2}{|c|}{$\begin{array}{l}\text { Sesuai } \\
\text { Suitable }\end{array}$} & \multicolumn{2}{|c|}{$\begin{array}{l}\text { Kurang sesuai } \\
\text { Least suitable }\end{array}$} & \multicolumn{2}{|c|}{$\begin{array}{c}\text { Pembatas } \\
\text { Constraint }\end{array}$} \\
\hline & ha & $\%$ & ha & $\%$ & ha & $\%$ & ha & $\%$ \\
\hline $\begin{array}{l}\text { Kualitas air } \\
\text { Water quality }\end{array}$ & 26.834 & 94 & 1.685 & 6 & 0 & 0 & 0 & 0 \\
\hline $\begin{array}{l}\text { Infrastruktur } \\
\text { Infrastructure }\end{array}$ & 11.456 & 40 & 16.712 & 59 & 351 & 1 & 0 & 0 \\
\hline $\begin{array}{l}\text { Pemanfaatan lahan } \\
\text { Land use type }\end{array}$ & 5.423 & 19 & 6.292 & 22 & 9.139 & 32 & 7.665 & 27 \\
\hline $\begin{array}{l}\text { Total kelayakan lahan } \\
\text { Overall suitability of site }\end{array}$ & 8.789 & 31 & 12.065 & 42 & 0 & 0 & 7.665 & 27 \\
\hline
\end{tabular}

Dukungan infrastruktur untuk kegiatan budidaya ikan lele yang masuk dalam ketegori sangat sesuai seluas 11.456 ha $(40 \%)$, selebihnya seluas 16.712 ha (59\%) masuk dalam kategori sesuai dan kategori kurang sesuai seluas 351 ha (1\%) yang tersebar di Parung dan Kemang (Gambar 4c).
Dengan menggabungkan seluruh parameter dan sub-model, akhirnya diperoleh tingkat kesesuaian lahan untuk budidaya ikan lele (Gambar 5 dan Tabel 5). Dari total luasan potensial untuk budidaya ikan lele (28.519 ha), kategori sangat sesuai ditemukan sekitar 8.789 ha (31\%). Kategori sesuai ditemukan sebesar 
12.065 ha (42\%). Lokasi dengan kategori sangat sesuai umumnya didukung oleh kondisi kualitas perairan yang baik, pemanfaatan lahan yang sesuai, dan infrastruktur yang memadai. Secara umum lokasi ini tersebar secara merata di keempat kecamatan minapolitan Kabupaten Bogor, meliputi Kecamatan Ciseeng, Kecamatan Gunung Sindur, Kecamatan Parung, dan Kecamatan Kemang (Gambar 5).

Analisis spasial yang diperoleh dari penelitian ini menunjukkan hasil yang sangat revelan dengan penetapan Kecamatan Ciseeng sebagai sentra pengembangan minapolitan, dan Kecamatan Gunung Sindur, Kecamatan Parung, dan Kecamatan Kemang sebagai daerah penyangga. Dari hasil kunjungan lapangan menunjukkan bahwa aktivitas kegiatan budidaya ikan lele di Kecamatan Ciseeng sudah berjalan dengan baik, termasuk di daerah penyangganya.

\section{Implementasi Estimasi Produksi}

Hasil analisis kesesuian lahan menunjukkan potensi yang cukup besar untuk pengembangan budidaya ikan lele di kawasan minapolitan Kabupaten Bogor. Tabel 6 menunjukkan estimasi produksi berdasarkan tingkat tek- nologi dan kesesuaian lahan budidaya ikan lele.

Pada umumnya pembudidaya ikan lele di kawasan minapolitan Kabupaten Bogor sudah menerapkan teknologi semi-intensif dan tradisional, dengan kisaran produksi per siklus per $\mathrm{m}^{2}$ antara $15-30 \mathrm{~kg}$. Berdasarkan data statistik menunjukkan bahwa produksi ikan lele dari kawasan minapolitan sebesar $24.072,98$ ton dari luas areal 1.075,94 ha atau setara dengan $2,24 \mathrm{~kg} / \mathrm{m}^{2}$ (Anonim, 2010). Dengan asumsi produktivitas lahan sama dengan tahun 2010 dan luasan areal kesesuaian yang diperoleh dari hasil penelitian ini menjadi 20.854 ha di mana $20 \%$ dari areal tersebut diperuntukkan kolam budidaya lele, maka produksi lele akan meningkat mendekati sekitar 93,300 ton dengan menggunakan teknologi tradisional. Jika tingkat teknologi yang diterapkan adalah semiintensif, maka peningkatan produksi akan terjadi secara signifikan yaitu mencapai 625.620 ton. Apabila nilai produksi berdasarkan teknologi tradisional tersebut dapat diimplementasikan maka produksi lele dari wilayah minapolitan Bogor akan mengisi target produksi nasional sebesar 175,000 ton.

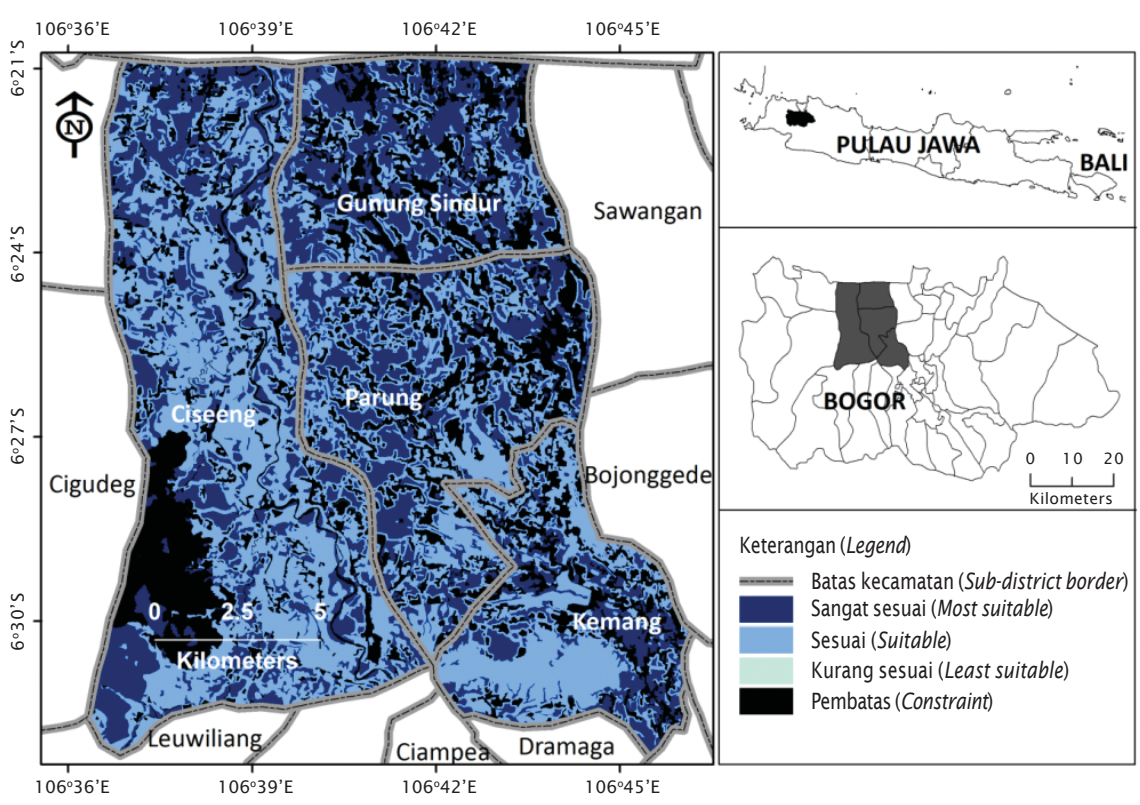

Gambar 5. Peta akhir kesesuaian lahan budidaya ikan lele di kawasan minapolitan Kabupaten Bogor Provinsi Jawa Barat

Figure 5. Final map of suitability site for catfish aquaculture in the minapolitan area of Bogor District West Java Province 
Tabel 6. Prakiraan produksi ikan lele konsumsi sesuai dengan tingkat kesesuaian lahan dan tingkat teknologi yang digunakan di kawasan minapolitan Kabupaten Bogor

Table 6. Production estimation for catfish based on suitability site and applied technology in the minapolitan area of Bogor District

\begin{tabular}{|c|c|c|c|}
\hline \multirow[t]{2}{*}{$\begin{array}{l}\text { Kesesuaian Iahan } \\
\text { Suitability site }\end{array}$} & \multirow{2}{*}{$\begin{array}{l}\text { Luasan } \\
\text { Area } \\
\text { (ha) }\end{array}$} & \multicolumn{2}{|c|}{$\begin{array}{l}\text { Produksi berdasarkan } \\
\text { tingkat teknologi } \\
\text { Estimation production } \\
\text { based on applied technology (ton) }\end{array}$} \\
\hline & & $\begin{array}{c}\text { Semi intensif } \\
(\text { Semi intensive) }\end{array}$ & $\begin{array}{c}\text { Tradisional } \\
\text { (Traditional) }\end{array}$ \\
\hline $\begin{array}{l}\text { Sangat se suai } \\
\text { Most suitable }\end{array}$ & 8.789 & 263.670 & 39.329 \\
\hline $\begin{array}{l}\text { Sesuai } \\
\text { Suitable }\end{array}$ & 12.065 & 361.950 & 53.988 \\
\hline Jumlah & 20.854 & 625.620 & 93.317 \\
\hline \multicolumn{4}{|c|}{$\begin{array}{l}\text { Keterangan (Note): } \\
\text { Pemanfaatan lahan produktif diproyeksikan hanya sebesar } 20 \% \text { untuk tipe } \\
\text { lahan sangat sesuai dan sesuai. Perhitungan pada tabel di atas mengambil nilai } \\
\text { tengah rata-rata pada nilai kisaran produksi }\end{array}$} \\
\hline
\end{tabular}

\section{Strategi Pengembangan Budidaya Ikan Lele}

Sistem usaha budidaya ikan lele di kawasan minapolitan Kabupaten Bogor terdiri atas tiga segmen usaha yaitu (Nugroho, 2011): (1) pembenihan (proses menghasilkan benih sampai dengan ukuran 2-3 cm dengan lama pemeliharaan sekitar 20 hari), (2) pendederan (segmen usaha mendederkan benih ukuran 2$3 \mathrm{~cm}$ sampai dengan ukuran 10-12 cm dengan lama usaha 1-2 bulan), dan (3) pembesaran (segmen usaha membesarkan ikan dari ukuran 10-12 cm menjadi ikan konsumsi ukuran bobot 125-150 g dengan lama pemeliharaan sampai dengan 2 bulan). Ketiga segmen usaha tersebut sudah terzonasi dengan baik di kawasan minapolitan Kabupaten Bogor. Pembudidaya secara alamiah sudah menyesuaikan daerahnya masing-masing berdasarkan kriteria keperluan lingkungan yang optimum untuk segmen usahanya. Perkembangan ketiga segmen tersebut tidak terlepas dari permasalahan yang dihadapi baik sifatnya teknis maupun non teknis.

Permasalahan utama pada segmen pembenihan yaitu masih sulitnya diperoleh sumber indukan yang berkualitas. Pada umumnya petani pembenih menggunakan indukan berasal dari hasil pilihan (ikan dipilih yang besar-besar dari populasi) yang berasal dari petani pembesar (ikan dengan ukuran terlalu besar yang tidak diterima pasar). Hanya sebagian kecil petani pembenih yang sudah menggunakan indukan yang bersertifikat. Penggunaan indukan yang kurang berkualitas, akan menghasilkan benih ikan yang berkualitas rendah. Dampaknya akan dirasakan langsung oleh petani pembesar, ikan yang dipeliharanya lambat tumbuh pada akhirnya biaya pakan tinggi sehingga marjin usaha menjadi kecil. Permasalahan teknis lainnya yang dijumpai adalah rendahnya sintasan benih, dikarenakan banyak kematian saat ikan umur 1-2 minggu dari waktu menetas. Hal ini sangat erat kaitannya dengan kualitas indukan yang dipergunakan, manajemen pakan induk, dan kriteria pemilihan induk saat pemijahan.

Pada segmen pendederan, hal yang banyak dikeluhkan oleh petani di kawasan minapolitan Kabupaten Bogor, yaitu rendahnya sintasan benih ukuran dederan. Masalah ini sangat erat kaitannya dengan lingkungan pemeliharaan (kualitas air). Persepsi masyarakat masih 
beranggapan bahwa ikan lele adalah ikan yang kebal pada lingkungan yang jelek, padahal tidak demikian untuk ikan lele ukuran benih/ dederan. Kondisi kualitas air optimum untuk keperluan pendederan beberapa parameter penentu adalah suhu air dan kadar amonia (Hardjamulia et al., 1992). Suhu yang ideal untuk ikan lele adalah $28^{\circ} \mathrm{C}-30^{\circ} \mathrm{C}$. Fluktuasi suhu lebih dari $4^{\circ} \mathrm{C}$ mengakibatkan stres dan pada akhirnya ikan mudah kena penyakit sehingga dapat menyebabkan kematian. Pengetahuan petani tentang sifat-sifat biologi ikan lele menjadi persyaratan utama yang harus dimiliki, sehingga para petani dapat mengaplikasikan dan menyiasatinya apabila ada permasalahan lingkungan yang muncul.

Hal lain yang menyebabkan banyak kehilangan pada waktu pendederan adalah sifat kanibalisme ikan lele. Hal ini dapat diatasi dengan jalan melakukan grading pada saat awal sebelum ikan ditebar ke kolam pendederan, kondisi ikan yang hampir seragam ukurannya dapat mengurangi tingkat kanibalisme.

Kendala utama pada segmen pembesaran adalah harga pakan yang terlalu mahal, dibandingkan dengan kondisi harga jual ikan ukuran konsumsi, sehingga petani umumnya mendapatkan marjin kecil. Pada kondisi demikian petani melakukan upaya/berinisiatif mencari pakan pengganti (pakan buatan). Pembudidaya umumnya menggunakan limbah (limbah potong ternak ayam atau produk olahan daging rijek) sebagai pakan yang diberikan secara langsung ke ikan lele. Hal ini bila berlangsung terus-menerus dikhawatirkan akan mengganggu lingkungan, baik itu lingkungan kolam budidaya atau lingkungan sekitarnya, bahkan tidak mustahil akan berdampak pada aspek pemasaran.

Untuk memperkecil atau menghilangkan permasalahan yang muncul dalam usaha pengembangan budidaya ikan lele di kawasan minapolitan dapat ditempuh dengan berbagai langkah strategi di antaranya:

1. Perbaikan kualitas induk. Diupayakan petani memperoleh indukan yang bersertifikat, apabila hal tersebut tidak bisa dicapai maka hal yang dapat dilakukan oleh petani pembenih yaitu mengusahakan agar indukan jantan dan betina yang dipijahkan tidak berasal dari satu keturunan. Induk pejantan bisa didapatkan dari daearah lain misalnya untuk induk betina dihasilkan dari proses seleksi di farm sendiri sedangkan pejantan didapatkan dari daerah yang jauh dari lokasi farm dan yakin induk yang digunakan tidak sedarah (tidak terjadi perkawinan sedarah "inbreeding"). Selain itu, peran instansi penelitian dan pengembangan pemerintah dalam memperkenalkan indukan berkualitas ke pengguna (pembudidaya) diharapkan dapat memperbaiki kualitas induk.

2. Perbaikan kualitas pakan induk dan lingkungan pemeliharaannya. Pakan induk yang dipersyaratkan agar menghasilkan kualitas benih unggul memiliki kadar protein minimal $30 \%$ dan pemberiannya 1,8 sampai dengan $2 \%$ per bobot biomassa per hari. Agar indukan nyaman dalam kolam pemeliharaan persyaratan khusus yang diperlukan meliputi: kolam induk dapat menggunakan kolam dengan dinding beton dan dasar dari tanah. Luasan $50 \mathrm{~m}^{2}$ dapat menampung induk 70-120 kg induk (jantan dan betina dipisah). Air masuk dapat diatur dengan debit 4-7 L/menit. Kedalaman kolam 80-100 cm. Untuk merangsang pembentukan gonad pada musim kemarau dapat dilakukan dengan menurunkan dan menaikkan permukaan air kolam. Dengan kondisi tersebut selain akan menghasilkan benih yang berkualitas, juga akan mempercepat masa pemulihan induk setelah dipijahkan dan akan meningkatkan produktivitas indukan.

3. Permasalahan kematian benih umur 1-2 minggu, juga dipengaruhi oleh kualitas indukan, terutama ditentukan pada pemilihan induk untuk dipijahkan. Pemilihan induk dengan kualitas telur yang baik akan menentukan tingkat penetasan dan kualitas larva, dan tentunya akan menentukan sintasan benih pada proses berikutnya. Permasalahan ini dapat diupayakan secara teknis yaitu melalui pemeriksaan kematangan gonad induk betina dapat dilakukan melalui proses kanulasi dengan menggunakan kateter diameter $3 \mathrm{~mm}$. Telur yang cukup baik sebagai syarat untuk proses pemijahan memiliki ciri-ciri: diameter telur berkisar antara 1,1-1,3 mm; berukuran seragam, warna jernih, jika dicek inti telur sudah ke tepi. Sedangkan induk jantan diperiksa dengan melihat kelamin. Kelamin ikan lele matang gonad berwarna kemerahan, kelamin panjang sebaiknya dapat mencapai sirip anal, dan tidak bengkok. Dalam memeriksa kematangan gonad, usahakan sesingkat dan jangan sampai 
menimbulkan luka pada induk karena akan mempengaruhi pemijahan. Untuk membantu kematangan telur secara serentak, dapat digunakan hormon HCG. Hal lain yang harus diperhatikan adalah keperluan pakan benih harus tercukupi baik jumlah maupun kualitasnya (tepat waktu, mutu, dan jumlah).

4. Untuk meningkatkan marjin usaha para petani pembesar dapat dilakukan melalui penyediaan benih berkualitas, sehingga dapat cepat tumbuh dengan masa pemeliharaan yang singkat dan penyediaan pakan murah agar diperoleh marjin usaha tinggi. Langkah-langkah yang perlu diupayakan untuk penyediaan pakan murah/ ekonomis diperlukan kerja sama yang baik antara pemerintah, kelompok tani, dan pengusaha. Pembekalan pengetahuan pembuatan pakan secara mandiri dengan menggunakan bahan baku lokal spesifik, merupakan alternatif terbaik agar keberlanjutan usaha ini akan tetap memperhatikan lingkungan.

\section{KESIMPULAN}

Berdasarkan hasil kajian lahan pada empat kecamatan wilayah pengembangan minapolitan Kabupaten Bogor menunjukkan bahwa kondisi kualitas perairan masih mendukung untuk pengembangan budidaya ikan lele. Analisis spasial kesesuaian lahan dari total potensial area sebesar 28.519 ha menunjukkan luasan sekitar 20.854 ha dengan kategori sangat sesuai ( 8.789 ha) dan sesuai (12.065 ha). Lokasi ini tersebar secara merata di empat kecamatan minapolitan. Berdasarkan tingkat teknologi yang berkembang di Kabupaten Bogor, dengan memanfaatkan hanya $20 \%$ dari luasan lahan tersebut dapat memproduksi dalam satu siklus sekitar 625.620 ton dengan teknologi semi-intensif atau 93.317 ton dengan teknologi tradisional. Implementasi dari analisis kesesuaian lahan ini harus didukung dengan strategi pengembangan mulai dari segmen pembenihan sampai pada segmen pembesaran. Hasil dari penelitian ini diharapkan dapat menjadi data dasar dan masukkan bagi instansi terkait yang berguna bagi perencanaan dan pemanfaatan lahan untuk mendukung pelaksanaan minapolitan.

\section{UCAPAN TERIMA KASIH}

Penulis mengucapkan terima kasih kepada Dinas Perikanan dan Peternakan Kabupaten
Bogor atas bantuannya selama kegiatan lapangan. Kami juga mengucapkan terima kasih kepada tim survai minapolitan: Prof. Dr. Achmad Sudradjat, Idil Adri, dan Imam Taufik yang telah membantu kelancaran pengumpulan data lapangan. Penelitian ini merupakan bagian dari penelitian Kajian Kesesuaian Lahan untuk Minapolitan Pusat Penelitian dan Pengembangan Perikanan Budidaya Tahun Anggaran 2011.

\section{DAFTAR ACUAN}

Anonim. 2001. Peraturan Pemerintah Republik Indonesia No. 82 tentang pengelolaan kualitas air dan pengendalian pencemaran air, $46 \mathrm{hlm}$.

Anonim. 2010. Masterplan minapolitan Kabupaten Bogor. Kerja sama Bappeda Kabupaten Bogor dengan Pusat Studi Pembangunann Pertanian Desa, Institut Pertanian Bogor, $105 \mathrm{hlm}$.

Clark, W.A.V. \& Hosking, P.L. 1986. Statistical Methods for Geographers. John Wiley \& Sons, Inc., 513 pp.

Burrough, P.A. \& McDonnell, R.A. 1998. Principle of geographical information systems. Oxford University Press, 327 pp.

Durborow, R.M. 2000. Catfish Farming in Kentucky. Aquaculture Program Kentucky State University Frankfort, Kentucky, 111 pp.

Hardjamulia, A., Sumantri, S., Utami, R., Komarudin, O., Sadeli, D., Widiyati, A., Praseno, O., Insan, I., Bastiawan, D., Affiati, N., Chumaidi, \& Suhenda, N. 1992. Pedoman teknis pembenihan ikan lele (Clarias batrachus). Seri pengembangan hasil penelitian perikanan No. PHP/KAN/PT/20/ 1992. Badan Penelitian dan Pengembangan Pertanian. Departemen Pertanian, $54 \mathrm{hlm}$.

Hollingsworth, C.S., Baldwin, R., Wilda, K., Ellis, R., \& Soares, S. 2006. Best Management Practices for Finfish Aquaculture in Massachusetts. Western Massachusetts Center for Sustainable Aquaculture. University of Massachusetts Extension, 54 pp.

Hossain, M.S., Chowdhury, S.R., Das, N.G., \& Rahaman, M.M. 2007. Multi-criteria evaluation approach to GIS-based land-suitability classification for tilapia farming in Bangladesh. Aquaculture International, 15: 425-443.

Hossain, M.S., Chowdhury, S.R., Das, N.G., Sharifuzzaman, S.M., \& Sultana, A. 2009. Integration of GIS and multicriteria decision 
analysis for urban aquaculture development in Bangladesh. Landscape and Urban Planning, 90: 119-133.

Johnson, K. \& McChow, J. 2001. Using ArcGIS spatial analysis. Environmental Systems Research Institute (ESRI), Inc, USA, 236 pp.

Malczewski, J. 1999. GIS and mutlicriteria decision analysis. John Wiley \& Sons. New York, $392 \mathrm{pp}$.

Morain, S. 1999. GIS Solution in Natural Resource Management: Balancing the Technical-Political Equation. OnWord Press. USA, $361 \mathrm{pp}$.

Nath, S.S., Bolte, J.P., Ross, L.G., \& AguilarManjarrez, J. 2000. Applications of geographical information systems (GIS) for spatial decision support in aquaculture. Aquacultural Engineering, 23: 233-278.

Nugroho, E. 2011 . Kiat agribisnis lele. Panduan teknis dan non teknis pembenihan dan pembesaran. Penebar Swadaya, Jakarta, 66 hlm.

Purba, N.P. \& Khan, A.M.A. 2010. Karakateristik Fisika-Kimia Perairan Pantai Dumai pada Musim Peralihan. J. Akuatika, I(1): 69-83.

Radiarta, I N., Albasri, H., \& Saputra, A. 2009. Pemetaan kelayakan lahan untuk pengembangan budidaya ikan nila di Kecamatan Wajak Kabupaten Malang Provinsi Jawa
Timur. Dalam: Djumanto, Dwiyitno, Chasanah, E., Heruwati, E.S., Irianto, H.E., Saksono, H., Lelana, I.Y.B., Basmal, J., Murniyati, Murwantoko, Probosunu, N., Peranginangin, R., Rustadi, \& Ustadi (Eds.), Prosiding Seminar Nasional Tahunan VI Hasil Penelitian Perikanan dan Kelautan Tahun 2009; Jilid I: Budidaya Perikanan. Jurusan Perikanan dan Kelautan, Fakultas Pertanian Universitas Gadjah Mada, Yogyakarta; Indonesian Network on Fish Health Management, Bogor dan Badan Riset Kelautan dan Perikanan, Jakarta. RB-1 8, hlm. 1-10.

Saaty, T.L. 1977. A Scaling Method for Priorities in Hierarchical Structures. J. of Mathematical Psychology, 15: 234-281.

Salam, M.A., Khatun, N.A., \& Ali, M.M. 2005. Carp farming potential in Barthatta Upazilla, Bangladesh: a GIS methodological perspective. Aquaculture, 245: 75-87.

Swann, L. 1996. A Fish Farmer's Guide to Understanding Water Quality. Illinois-Indiana Sea Grant Program. Department of Animal Sciences. Purdue University. Fact Sheet AS-503, 8 pp.

Treece, G.D. 2000. Site selection. In Stickney (Ed.). Encyclopedia of aquaculture. A WileyInterscience Publication, p. 869-879. 